\title{
Anastomosis technique for pancreatojejunostomy and early removal of drainage tubes may reduce postoperative pancreatic fistula
}

Hiromichi Kawaida*, Hiroshi Kono, Hidetake Amemiya, Naohiro Hosomura, Mitsuaki Watanabe, Ryo Saito, Yuuki Nakata, Katsutoshi Shoda, Hiroki Shimizu, Shinji Furuya, Hidenori Akaike, Yoshihiko Kawaguchi, Makoto Sudo, Masanori Matusda, Jun Itakura, Hideki Fujii and Daisuke Ichikawa

\begin{abstract}
Background: Postoperative pancreatic fistula (POPF) is one of the most serious complications after pancreaticoduodenectomy (PD). Various factors have been reported as POPF risks, but the most serious of these is soft pancreas. To reduce POPF occurrences, many changes to the PD process have been proposed. This study evaluates short-term results of anastomosis technique for PD.

Methods: In total, 123 patients with soft pancreases who had undergone PD at Yamanashi University between January 2012 and August 2020 were retrospectively analyzed. We divided these patients into two groups depending on the time PD was performed: a conventional group $(n=67)$ and a modified group $(n=56)$.
\end{abstract}

Results: The rate of clinically relevant POPF was significantly lower in the modified group than that in the conventional group (5.4\% vs $22.4 \%, p$ value $<0.001$ ), with there being only one case of POPF in the modified group. There were no cases of POPF-related hemorrhaging in the modified group. On the third day after the operation, the amylase levels in the drainage fluid for the modified group became less than half (1696 vs $650 \mathrm{U} / \mathrm{L}$ ). Multivariate analysis showed that the modified method was the independent predictors to prevent clinical POPF ( $p$ value $=0.002$ ).

Conclusions: Our novel anastomosis technique for pancreatojejunostomy reduced POPF in PD, especially in cases where the patient had a soft pancreas.

\section{Introduction}

Pancreaticoduodenectomy (PD) is still the only curative treatment option for malignant and some borderline/benign tumors of the pancreatic head and periampullary region despite the development of various other treatments. With advances in surgical techniques and perioperative management, the operative mortality of PD in high-volume centers has reduced to less than $3 \%[1-3]$.

* Correspondence: kawaidah@yamanashi.ac.jp

First Department of Surgery, Faculty of Medicine, University of Yamanashi, 1110 Shimokato, Chuo-shi, Yamanashi 409-3898, Japan
However, incidences of postoperative pancreatic fistula (POPF) have still been reported to be as high as 10\% [4-7].

POPF is one of the most serious complications that can result from PD. POPF occurs when there is a pancreatic juice leakage from a surgically exfoliated surface and/or anastomosis. Many previous studies have described several risk factors for POPF, such as gender (male) [8], a high body mass index (BMI) [9], the anastomotic method $[6,10]$, and the use of an external stent [11]. However, the greatest risks are having a small pancreatic duct $(\leq 3 \mathrm{~mm})$ or a soft pancreas $[6,10,12-17]$.

C C The Author(s). 2020 Open Access This article is licensed under a Creative Commons Attribution 4.0 International License, which permits use, sharing, adaptation, distribution and reproduction in any medium or format, as long as you give appropriate credit to the original author(s) and the source, provide a link to the Creative Commons licence, and indicate if changes were made. The images or other third party material in this article are included in the article's Creative Commons licence, unless indicated otherwise in a credit line to the material. If material is not included in the article's Creative Commons licence and your intended use is not permitted by statutory regulation or exceeds the permitted use, you will need to obtain permission directly from the copyright holder. To view a copy of this licence, visit http://creativecommons.org/licenses/by/4.0/ The Creative Commons Public Domain Dedication waiver (http://creativecommons.org/publicdomain/zero/1.0/) applies to the data made available in this article, unless otherwise stated in a credit line to the data. 
In those cases, the anastomosis of the pancreatic duct can be difficult, which may cause anastomotic leakage. Furthermore, overactive exocrine functioning may be deeply involved in the development of POPF, which sometimes causes intraperitoneal abscesses and subsequent lethal hemorrhaging. Therefore, various surgical and perioperative attempts have been made to reduce incidences of POPF. However, there are still many controversies around the anastomosis technique, such as pancreaticojejunostomy (PJ) vs pancreaticogastrostomy $[18,19]$ and the use of stents [20-22]. Our hospital has conventionally used the PJ method, but our practice has been modified in recent years.

The purpose of this study is to introduce a novel anastomosis technique and analyze its treatment results, including incidences of POPF compared with conventional techniques for patients with a soft pancreas. Furthermore, we analyzed the risk factors of POPF in all cases.

\section{Materials and methods Patients}

A total of 237 patients had undergone PD at Yamanashi University between January 2012 and August 2020. Among them, patients who were judged to have a hard pancreas based on intraoperative findings by a surgeon or with a main pancreatic duct diameter of over $2 \mathrm{~mm}$ by magnetic resonance cholangiopancreatography (MRCP) were 114. Patients with a past history of pancreatitis were also included in this group. Of these, 13 patients had POPF. In the conventional method, patients with Soft pancreas tended to develop pancreatic fistula. Therefore, to focus on cases of soft pancreas, we excluded them in this study.

The remaining 123 patients who were judged to have a soft pancreas based on intraoperative findings by surgeons, and patients with a main pancreatic duct diameter of $2 \mathrm{~mm}$ or less were selected. We divided them into two groups according to the PJ techniques. Fifty-six patients underwent the modified technique (from April 2017 to August 2020; M group), and the remaining 67 patients underwent the conventional technique (from January 2012 to March 2017; C group). The clinical characteristics and pathological examinations were collected from electronic medical records. To supplement the perioperative data, we examined a review of the surgical and anesthetic charts of each patient. This study was approved by the Human Research Ethics Committee of Faculty of Medicine, University of Yamanashi (No. H30232).

\section{Surgical technique}

For the patients with pancreatic cancer, we performed a subtotal stomach-preserving pancreatoduodenectomy. For the patients with other diseases, we performed a pylorus-preserving pancreatoduodenectomy. Portal vein and/or superior mesenteric vein resection was performed in combination with PD in patients with possible or definite tumor invasion. Reconstruction was performed according to the modified Child's technique. After the jejunal limb was brought up through the antecolic route, we performed an end-to-side PJ first, followed by an end-to-side hepaticojejunostomy and end-to-side gastrojejunostomy. Two closed drainage tubes were routinely placed near the region where the PJ was being performed and at the underside of the hepaticojejunostomy. All the operations were performed by a hepato-pancreato-biliary team.

\section{Conventional anastomosis for $\mathrm{PJ}$}

The outer layer of the end-to-side PJ was sutured in concentric circles centered on the duct-to-mucosa anastomosis. The anastomosis was constructed using 4-0 Vascufil (double-armed polybutester, Tyco Healthcare Co., USA).

(1) First, a 5-Fr external stenting tube was inserted into the pancreatic duct through the anastomotic site of the jejunal wall. (2) The duct-to-mucosa anastomosis was performed in an end-to-side fashion with eight absorbable interrupted sutures using 5-0 PDS-II (Johnson and Johnson Co., Tokyo, Japan) and an external stent from the main pancreatic duct (Fig. 1a). (3) Before the sutures of the duct-to-mucosa were tied, the needle of the 4-0 Vascufil was used to penetrate the pancreatic parenchyma from the cut surface of the pancreas to the posterior wall. The serous muscle layer of the jejunum was then penetrated in three small steps so as not to penetrate through all the layers of the wall. This was performed from the outside toward the insertion portion of the stent tube. The anastomosis of the posterior wall was performed at three places in total. (4) The anastomosis of both the upper and lower edges was performed. The needle of the 4-0 Vascufil penetrated through the pancreatic parenchyma from the wall of the pancreas to the cut surface near the duct-to-mucosa anastomosis. The serous muscle layer of the jejunum was then penetrated in three steps (arrows in Fig. 1b) from near the insertion portion of the stent tube toward the outside (Fig. 1b). (5) Then, all three sutures of the posterior wall threads were tied. Subsequently, the sutures of the duct-to-mucosa were tied. (6) Finally, the anastomosis of the anterior pancreatic wall was performed. The needle of the 4-0 Vascufil penetrated through the pancreatic parenchyma from the anterior wall of the pancreas to the cut surface near the duct-to-mucosa anastomosis. The serous muscle layer of the jejunum was then penetrated in three steps from near the insertion portion of the stent tube toward the outside. 
a

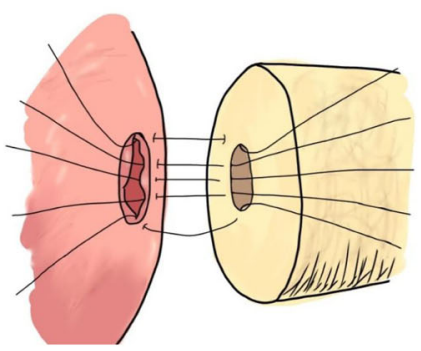

c

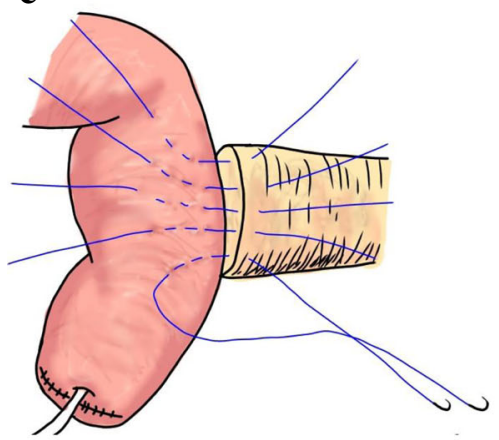

b

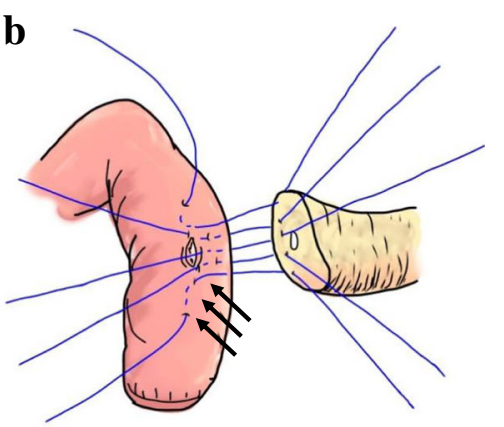

d

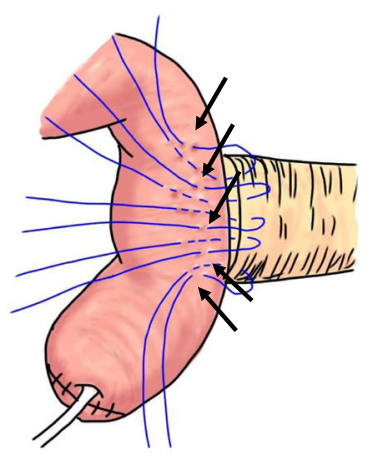

e

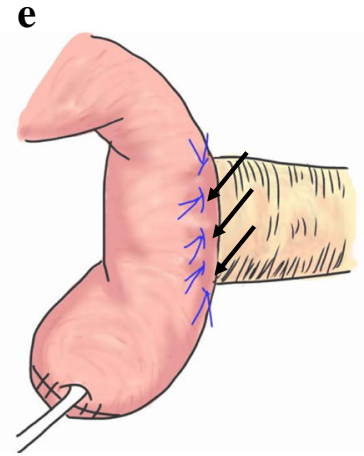

Fig. 1 Schemes of PJ. a The duct-to-mucosa anastomosis was performed in an end-to-side fashion with eight absorbable interrupted sutures using 5-0 PDS-II with an external stent from the main pancreatic duct. $\mathbf{b}$ Before the sutures of the duct-to-mucosa were tied, the needle of the 4-0 Vascufil penetrated through the pancreatic parenchyma from the cut surface of the pancreas to the posterior wall. The serous muscle layer of the jejunum was then penetrated in three small steps (so as not to penetrate through all the layers of the wall) from the outside toward the insertion portion of the stent tube. The anastomosis of the posterior wall was performed at three places in total (arrows in $\mathbf{b}$ ). The anastomosis of both the upper and lower edges was performed. The needle of the double-armed 4-0 Vascufil penetrated through the pancreatic parenchyma from the wall of the pancreas to the cut surface near the duct-to-mucosa anastomosis. The serous muscle layer of the jejunum was then penetrated in three steps from near the insertion portion of the stent tube toward the outside (arrows). c The anastomosis of the anterior pancreatic wall was performed similarly for both edges. These were performed at three places in total. $\mathbf{d}$ In the anterior wall and both the upper and lower edges, the needle at the pancreatic side of the double-armed 4-0 Vascufil was sutured at a point 5-8 mm from the lateral side of the previous suture, which penetrated the jejunal seromuscular wall like a triangular mattress suite (arrows). e All five sutures were tied gently to prevent tearing of the pancreatic parenchyma. This procedure completely covered the needle holes of the pancreatic wall by the jejunal serosa (arrows)

These procedures were performed at three places in total (Fig. 1c).

\section{Modified anastomosis: triangular mattress suite method} We made changes to the anastomosis of the anterior pancreatic wall and both the upper and lower edges. The needle at the pancreatic side of the double-armed 4-0 Vascufil was sutured at a point $5-8 \mathrm{~mm}$ to the lateral side of the previous suture, which penetrated the jejunal seromuscular wall like a triangular mattress suite (arrows in Fig. 1d). Then, all five sutures were tied gently to prevent the tearing of the pancreatic parenchyma. 
This procedure completely covered the needle holes of the pancreatic wall with the jejunal serosa (arrows in Fig. 1e).

\section{Postoperative management}

Prophylactic somatostatin analogs were not administered to prevent POPF. The amylase level in the drainage fluid (D-Amy) was routinely measured on postoperative days (PODs) 1 and 3. The drainage tube was removed on POD 3 if the drainage fluid was clear regardless of the amount of drainage fluid or D-Amy, indicating that no bacterial infection existed. POPF was diagnosed according to the International Study Group of Pancreatic Fistula criteria [4].

\section{Evaluated factors}

The following factors that may be associated with the formation of POPF were analyzed in this study: sex, age, BMI, white blood cell (WBC) count in peripheral blood, C-reactive protein (CRP), serum albumin, hemoglobin A1c (HbA1c), operative time, volume of blood loss, intraoperative blood transfusion, D-Amy, and surgical procedures.

\section{Statistical analysis}

Data were expressed as the mean \pm standard deviation. Patient characteristics and intraoperative and postoperative factors between the two groups were compared using Chi-square statistics, Fisher's exact test and the Mann-Whitney $U$ test. Multivariate logical regression analyses were conducted to identify independent risk factor for POPF. Significance was defined as a $p$ value $<0.05$. The statistical analyses were performed using SPSS version 23.0 software (SPSS Inc., Chicago, IL, USA).

\section{Results}

\section{Patient characteristics}

There were no significant differences in sex, median age, serum albumin and $\mathrm{HbA1c}$ between the $\mathrm{C}$ group and $\mathrm{M}$ group. BMI was higher in the $\mathrm{M}$ group, but this was not significant. In intraoperative findings, volume of blood loss and frequencies of blood transfusion were not significant. However, for the mean operation time, the $\mathrm{M}$ group was significantly longer than the $\mathrm{C}$ group. The length of hospital stay was significantly shortened in modified group. Patient characteristics are shown in Table 1.

Table 1 Patients' characteristics and pathologic and operative details

\begin{tabular}{|c|c|c|c|}
\hline & Conventional $(n=67)$ & Modified $(n=56)$ & $p$ value \\
\hline Male/female & $44 / 23$ & $36 / 20$ & 0.874 \\
\hline Age (range) & $70(14-86)$ & $71(31-87)$ & 0.8 \\
\hline BMI $\left(\mathrm{kg} / \mathrm{m}^{2}\right)$ & $21.8 \pm 0.3$ & $23.0 \pm 0.5$ & 0.06 \\
\hline Albumin (g/dL) & $4.6 \pm 0.6$ & $4.0 \pm 0.1$ & 0.384 \\
\hline HbA1c (\%) & $5.8 \pm 0.1$ & $5.8 \pm 0.1$ & 0.959 \\
\hline Preoperative CRP (mg/dL) & $0.4 \pm 0.1$ & $0.4 \pm 0.1$ & 0.684 \\
\hline Preoperative biliary drainage (yes/no) & $27 / 40$ & $26 / 30$ & 0.498 \\
\hline \multicolumn{4}{|l|}{ Disease } \\
\hline CBD cancer & $24(35.8 \%)$ & $20(35.7 \%)$ & \\
\hline Ampullary tumor & $12(17.9 \%)$ & $9(16.1 \%)$ & \\
\hline Duodenal tumor & $5(7.5 \%)$ & $1(1.8 \%)$ & \\
\hline Pancreatic cancer & $5(7.5 \%)$ & $12(21.4 \%)$ & \\
\hline PNEN & $10(14.9 \%)$ & $2(3.6 \%)$ & \\
\hline IPMN & $7(10.4 \%)$ & $6(10.7 \%)$ & \\
\hline SPN & $2(3.0 \%)$ & $3(5.4 \%)$ & \\
\hline SCN & $1(1.5 \%)$ & 0 & \\
\hline Metastatic cancer & $1(1.5 \%)$ & 0 & \\
\hline Other disease & 0 & $3(5.4 \%)$ & \\
\hline Operative time (min) & $450 \pm 9$ & $497 \pm 14$ & 0.004 \\
\hline Blood loss (ml) & $772 \pm 64$ & $642 \pm 72$ & 0.181 \\
\hline Hospital stays & $33.5 \pm 1.8$ & $28.4 \pm 1.0$ & 0.023 \\
\hline
\end{tabular}

BMI Body mass index, HbA1c Hemoglobin A1c, CBD Common bile duct, PNEN Pancreatic neuroendocrine neoplasm, IPMN Intraductal papillary mucinous neoplasm, SPN Solid pseudopapillary neoplasm, SCN Serous cystic neoplasm, BTF Blood transfusion 
Comparisons of the postoperative laboratory data and amylase levels in the drainage fluid

There were no significant differences in the WBC count or CRP on PODs 1 and 3 between the $C$ group and $M$ group.

The D-Amy of the M group on POD 1 was similar to the $\mathrm{C}$ group (the $\mathrm{C}$ group vs the $\mathrm{M}$ group, $7738 \pm 1544$ vs $5122 \pm 869 \mathrm{U} / \mathrm{L})$. However, the D-Amy of the $\mathrm{M}$ group on POD 3 became less than half of that measured in the $\mathrm{C}$ group $(1696 \pm 914$ vs $650 \pm 133 \mathrm{U} / \mathrm{L})$ (Table 2).

\section{Incidence of POPF}

The date of the POPF instances is shown in Table 3. The rate of clinically relevant POPF was significantly lower in the $M$ group than in the $C$ group $(5.4 \%$ vs $22.4 \%, p$ value $<0.001$ ), having only one case of POPF in the $\mathrm{M}$ group. Furthermore, although there were three cases of POPF-related hemorrhaging in the $\mathrm{C}$ group, there were no such cases in the $M$ group. Mortality within 90 days was zero in both groups.

\section{Predicting factors and risk factors of POPF}

Univariate analysis showed that men, high-BMI patients, and conventional methods were significantly associated with clinically relevant POPF. Multivariate analysis also showed that men and high-BMI patients were independent risk factors for POPF, and the modified method was the independent predictors to prevent clinical POPF $(p$ value $<0.001)$ (Table 4).

\section{Discussion}

The rate of clinical POPF is still high at approximately 10-20\% after PD [23-27], and the most important risk factors are soft pancreases and non-dilated main pancreatic ducts $[28,29]$. Therefore, we focused on patients with soft pancreas and main pancreatic duct diameters of $2 \mathrm{~mm}$ or less when revising our techniques for the operation.

In our hospital, the rate of POPF from the conventional method was almost identical to that in previous

Table 2 Comparisons of the postoperative laboratory data and amylase levels in the drainage fluid

\begin{tabular}{llll}
\hline & $\begin{array}{l}\text { Conventional } \\
(\boldsymbol{n}=\mathbf{6 7})\end{array}$ & $\begin{array}{l}\text { Modified } \\
(\boldsymbol{n}=\mathbf{5 6})\end{array}$ & $\boldsymbol{p}$ value \\
\hline WBC on POD 1 $(/ \mu \mathrm{L})$ & $10548 \pm 358$ & $11292 \pm 468$ & 0.202 \\
WBC on POD 3 $(/ \mu \mathrm{L})$ & $9282 \pm 435$ & $9794 \pm 416$ & 0.404 \\
CRP on POD 1 $(\mathrm{mg} / \mathrm{dL})$ & $8.5 \pm 0.3$ & $9.1 \pm 0.4$ & 0.195 \\
CRP on POD 3 $(\mathrm{mg} / \mathrm{dL})$ & $13.8 \pm 0.9$ & $14.5 \pm 0.8$ & 0.572 \\
D-Amy on POD 1 $(\mathrm{U} / \mathrm{L})$ & $7738 \pm 1544$ & $5122 \pm 869$ & 0.166 \\
D-Amy on POD 3 $(\mathrm{U} / \mathrm{L})$ & $1696 \pm 914$ & $650 \pm 133$ & 0.315 \\
\hline
\end{tabular}

WBC White blood cell, CRP C-reactive protein, D-Amy amylase level in the drainage fluid
Table 3 Comparison of the incidence of postoperative pancreatic fistula

\begin{tabular}{llll}
\hline & $\begin{array}{l}\text { Conventional } \\
(\boldsymbol{n}=\mathbf{6 7})\end{array}$ & $\begin{array}{l}\text { Modified } \\
(\boldsymbol{n}=\mathbf{5 6})\end{array}$ & $\boldsymbol{p}$ value \\
\hline POPF & & & \\
Grade B or C & $15(22.4 \%)$ & $3(5.4 \%)$ & $<0.001$ \\
None or biochemical leakage & 52 & 53 & \\
\hline
\end{tabular}

POPF Postoperative pancreatic fistula

reports (22.4\%). However, the rate of POPF reduced significantly with the modified method, only occurring in 3 of every 56 cases (5.4\%). No patient has sepsis, postoperative intervention, or readmission in the $M$ group. Moreover, multivariate analysis showed that the modified method was an independent factor for preventing clinical POPF.

Of the 111 cases excluded in this study, 62 belonged to the $\mathrm{C}$ group. Of the 54 cases included in the $\mathrm{M}$ group, POPF was observed in 5 cases, and 1 of them was a non-stent case. In all cases including these, $\mathrm{M}$ group significantly reduced POPF compared to $\mathrm{C}$ group (C group, $17.8 \%$; $\mathrm{M}$ group, $7.4 \%$; $p$ value $=0.018$ ).

We routinely measured amylase levels in the D-Amy on PODs 1 and 3. Although the median D-Amy of the $M$ group on POD 1 was similar to that of the $C$ group, the median D-Amy of the M group on POD 3 had reduced to one third of the $\mathrm{C}$ group levels. This result suggests that our new method prevents the leakage of pancreatic fluid more effectively than the conventional method.

In recent years, a transpancreatic U-suture technique has been devised by Blumgart et al. [30]. Because of the simple method and excellent results, this method has been validated by many surgeons [31,32], and several surgeons have tried this modified method of novel anastomosis and reported the treatment results [28, 33-36]. This method prevents the tear of pancreatic parenchyma and the jejunum wall, which could be in close contact with the pancreatic cut surface. On the other hand, a transpancreatic U-suture technique might reduce blood flow in the pancreatic stump. Furthermore, if a transpancreatic U-suture is placed from the cranial section of the main pancreatic duct to the caudal section, it may cause stenosis of the main pancreatic duct.

On the other hand, our procedure does not include the problems listed above. That is, the pancreas and jejunum are sutured concentrically around the main pancreatic duct, so there is no concern about decreased blood flow of the pancreas. Main pancreatic duct stenosis can be avoided as the suture does not tighten the main pancreatic duct. By suturing in a concentric shape, the jejunum wall can have close contact with the whole pancreatic cut surface. Furthermore, the needlepenetrated holes in the anterior wall including both the 
Table 4 Predicting factors and risk factors of postoperative pancreatic fistula in all cases

\begin{tabular}{|c|c|c|c|c|c|c|}
\hline & \multicolumn{3}{|l|}{ Univariate analysis } & \multicolumn{3}{|c|}{ Multivariate analysis } \\
\hline & None or biochemical leakage $(n=105)$ & POPF B and C $(n=18)$ & $p$ value & Odds ratio & $95 \% \mathrm{Cl}$ & $p$ value \\
\hline Male/female & $64 / 41$ & $16 / 2$ & 0.059 & & & \\
\hline Age (range) & $69(14-87)$ & $68(30-83)$ & 0.775 & & & \\
\hline BMI $\left(\mathrm{kg} / \mathrm{m}^{2}\right)$ & $22.0 \pm 0.3$ & $24.2 \pm 0.5$ & $<0.001$ & 0.699 & $0.568-0.862$ & $<0.001$ \\
\hline Albumin (g/dL) & $4.0 \pm 0.5$ & $4.2 \pm 0.4$ & 0.019 & 0.993 & $0.285-3.460$ & 0.992 \\
\hline $\mathrm{HbA1c}(\%)$ & $5.8 \pm 0.1$ & $5.8 \pm 0.1$ & 0.705 & & & \\
\hline Operative time (min) & $470 \pm 9$ & $500 \pm 18$ & 0.179 & & & \\
\hline Blood loss (ml) & $736 \pm 55$ & $615 \pm 63$ & 0.364 & & & \\
\hline Conventional/modified & $52 / 53$ & $15 / 3$ & $<0.001$ & 0.083 & $0.018-0.388$ & 0.002 \\
\hline
\end{tabular}

upper and lower edges' walls of the pancreas can also be widely covered with the jejunum serosa by using triangular mattress suite method. As the needle-penetrated holes in the dorsal pancreatic wall are covered by the splenic vein and soft tissue, it does not cause POPF.

Although stent usage is also controversial, we routinely insert the external stent tube in the main pancreatic duct for patients with soft pancreases to prevent pancreatic trypsin from corroding the anastomotic site during the early period after surgery [20-22]. Also, the drainage tube was removed on POD 3 if the drainage fluid was clear. The timing of the drain removal is not defined. However, a previous study reports improved outcomes with early drain removal after pancreatoduodenectomy [37], and the prolonged placement of a drain might be a major cause of POPF as retrograde intra-abdominal infection may occur [38, 39].

To prevent clinical POPF, pancreato-biliary surgeons have tried various methods and reported their treatment results, including pancreaticoenterostomy $[18,19,28$, 33-36], the use of the pancreatic duct stenting [20-22], the management of the drainage tube [37-39], and somatostatin analogs [40-42]. However, the efficacy of these methods is still controversial. Although the present study has some limitations that were analyzed retrospectively and only presented data from a single institution, our surgical procedure and perioperative management have the possibility to reduce POPF.

\section{Conclusions}

We introduced a novel anastomosis technique for PJ. Although the present study has the limitations of only being based at a single institution, our surgical procedure and the early removal of the drainage tubes may reduce POPF in PD for patients with soft pancreases.

\section{Abbreviations}

PD: Pancreaticoduodenectomy; POPF: Postoperative pancreatic fistula; BMI: Body mass index; PJ: Pancreaticojejunostomy; MRCP: Magnetic resonance cholangiopancreatography; D-Amy: The amylase level in the drainage fluid; POD: Postoperative day; WBC: White blood cell; CRP: Creactive protein; HbA1c: Hemoglobin A1c

\section{Acknowledgements}

None

\section{Authors' contributions}

All authors helped to perform the research. Kawaida $\mathrm{H}$ actively involved in this study especially in statistical design. Concept and clinical design were conducted by seven surgeons (Kawaida H, Hosomura N, Watanabe M, Amemiya H, Yuuki Nakata, Kono H, and Ichikawa D). Acquisition of data was done by all physician (Hiromichi Kawaida, Hiroshi Kono, Hidetake Amemiya, Naohiro Hosomura, Mitsuaki Watanabe, Ryo Saito, Yuuki Nakata, Katsutoshi Shoda, Hiroki Shimizu, Shinji Furuya, Hidenori Akaike, Yoshihiko Kawaguchi, Makoto Sudo, Masanori Matusda, Jun Itakura, Hideki Fujii, and Daisuke Ichikawa). Interpretation of data and drafting the article were done by $\mathrm{H}$. Kawaida. Finally, this article was revised and approved by all 17 investigators. Thus, all 17 authors actively participated in this study.

\section{Authors' information}

Hiromichi Kawaida and Hiroshi Kono contributed equally to this work.

\section{Funding}

None

\section{Availability of data and materials}

The datasets generated during and/or analyzed during the current study are available from the corresponding author on reasonable request.

Ethics approval and consent to participate

This study was approved by the Human Research Ethics Committee of Faculty of Medicine, University of Yamanashi (No. H30232).

\section{Consent for publication}

Not applicable.

\section{Competing interests}

The authors declare that they have no competing interests.

Received: 13 July 2020 Accepted: 26 October 2020

Published online: 12 November 2020

\section{References}

1. Büchler MW, Wagner M, Schmied BM, Uhl W, Friess H, Z'graggen K. Changes in morbidity after pancreatic resection: toward the end of completion pancreatectomy. Arch Surg. 2003;138:1310-4.

2. Kimura W, Miyata H, Gotoh M, Hirai I, Kenjo A, Kitagawa Y, et al. A pancreaticoduodenectomy risk model derived from 8575 cases from a national single-race population (Japanese) using a web-based data entry system: the 30-day and in-hospital mortality rates for pancreaticoduodenectomy. Ann Surg. 2014;259:773-80.

3. Cameron $\mathrm{J}$, He J. Two thousand consecutive pancreaticoduodenectomies. J Am Coll Surg. 2015;220(4):530-6. 
4. Bassi C, Marchegiani G, Dervenis C, Sarr M, Abu Hilal M, Adham M, et al. International study group on pancreatic surgery (ISGPS), the 2016 update of the international study group (ISGPS) definition and grading of postoperative pancreatic fistula: 11 years after. Surgery. 2017;161:584-91.

5. Keck T, Wellner UF, Bahra M, Klein F, Sick O, Niedergethmann M, et al. Pancreatogastrostomy versus pancreatojejunostomy for reconstruction after pancreatoduodenectomy (RECOPANC, DRKS 00000767): perioperative and long-term results of a multicenter randomized controlled trial. Ann Surg. 2016:263:440-9.

6. Fu SJ, Shen SL, Li SQ, Hu WJ, Hua YP, Kuang M, et al. Risk factors and outcomes of postoperative pancreatic fistula after pancreaticoduodenectomy: an audit of 532 consecutive cases. BMC Surg. 2015;15:34.

7. Chen BP, Bennett S, Bertens KA, Balaa FK, Martel G. Use and acceptance of the international study Group for Pancreatic Fistula (ISGPF) definition and criteria in the surgical literature. HPB (Oxford). 2018;20:69-75.

8. Ferrone $C R$, Warshaw AL, Rattner DW, Berger D, Zheng H, Rawal B, et al. Pancreatic fistula rates after 462 distal pancreatectomies: staplers do not decrease fistula rates. J Gastrointest Surg. 2008;12:1691-7.

9. Seeliger H, Christians S, Angele MK, Kleespies A, Eichhorn ME, Ischenko I, et al. Risk factors for surgical complications in distal pancreatectomy. Am J Surg. 2010;200:311-7.

10. Hu BY, Wan T, Zhang WZ, Dong JH. Risk factors for postoperative pancreatic fistula: analysis of 539 successive cases of pancreaticoduodenectomy. World J Gastroenterol. 2016;22:7797-805.

11. Pedrazzoli S. Pancreatoduodenectomy (PD) and postoperative pancreatic fistula (POPF): a systematic review and analysis of the POPF-related mortality rate in 60,739 patients retrieved from the English literature published between 1990 and 2015. Medicine (Baltimore). 2017;96:e6858.

12. Ke Z, Cui J, Hu N, Yang Z, Chen H, Hu J, et al. Risk factors for postoperative pancreatic fistula: analysis of 170 consecutive cases of pancreaticoduodenectomy based on the updated ISGPS classification and grading system. Medicine (Baltimore). 2018;97(35):e12151.

13. Yang $Y M$, Tian $X D$, Zhuang $Y$, Wang WM, Wan YL, Huang YT. Risk factors of pancreatic leakage after pancreaticoduodenectomy. World J Gastroenterol. 2005;11(16):2456-61.

14. Liu QY, Zhang WZ, Xia HT, Leng JJ, Wan T, Liang B, et al. Analysis of risk factors for postoperative pancreatic fistula following pancreaticoduodenectomy. World J Gastroenterol. 2014;20(46):17491-7.

15. Ansorge C, Strommer L, Andren-Sandberg A, Lundell L, Herrington MK, Segersvard R. Structured intraoperative assessment of pancreatic gland characteristics in predicting complications after pancreaticoduodenectomy. Br J Surg. 2012;99:1076-82.

16. El Nakeeb A, Salah T, Sultan A, El Hemaly M, Askr W, Ezzat H, et al. Pancreatic anastomotic leakage after pancreaticoduodenectomy. Risk factors, clinical predictors, and management (single center experience). World J Surg. 2013;37:1405-18.

17. Bassi C, Falconi M, Molinari E, Salvia R, Butturini G, Sartori N, et al. Reconstruction by pancreaticojejunostomy versus pancreaticogastrostomy following pancreatectomy: results of a comparative study. Ann Surg. 2005;242:767-71.

18. Topal B, Fieuws S, Aerts R, Weerts J, Feryn T, Roeyen G, et al. Pancreaticojejunostomy versus pancreaticogastrostomy reconstruction after pancreaticoduodenectomy for pancreatic or periampullary tumours: a multicentre randomised trial. Lancet Oncol. 2013;14:655-62.

19. Figueras J, Sabater L, Planellas P, Muñoz-Forner E, Lopez-Ben S, Falgueras $L$, et al. Randomized clinical trial of pancreaticogastrostomy versus pancreaticojejunostomy on the rate and severity of pancreatic fistula after pancreaticoduodenectomy. Br J Surg. 2013;100:1597-605.

20. Motoi F, Egawa S, Rikiyama T, Katayose Y, Unno M. Randomized clinical trial of external stent drainage of the pancreatic duct to reduce postoperative pancreatic fistula after pancreaticojejunostomy. Br J Surg. 2012;99:524-31.

21. Pessaux P, Sauvanet A, Mariette C, Paye F, Muscari F, Cunha AS, et al. External pancreatic duct stent decreases pancreatic fistula rate after pancreaticoduodenectomy: prospective multicenter randomized trial. Ann Surg. 2011;253:879-85.

22. Poon RT, Fan ST, Lo CM, Ng KK, Yuen WK, Yeung C, et al. External drainage of pancreatic duct with a stent to reduce leakage rate of pancreaticojejunostomy after pancreaticoduodenectomy: a prospective randomized trial. Ann Surg. 2007:246:425-33.

23. Kanda M, Fujii T, Kodera Y, Nagai S, Takeda S, Nakao A. Nutritional predictors of postoperative outcome in pancreatic cancer. Br J Surg. 2011;98:268-74.
24. Lai EC, Lau SH, Lau WY. Measures to prevent pancreatic fistula after pancreatoduodenectomy: a comprehensive review. Arch Surg. 2009;144:1074-80.

25. Bassi C, Marchegiani G, Dervenis C, Sarr M, Hilal MA, Adham M, et al. The 2016 update of the international study group (ISGPS) definition and grading of postoperative pancreatic fistula: 11 years after. Surgery. 2017;161:584-91.

26. Keck T, Wellner UF, Bahra M, Klein F, Sick O, Niedergethmann M, et al. Pancreatogastrostomy versus pancreatojejunostomy for RECOnstruction after PANCreatoduodenectomy (RECOPANC, DRKS 0000767). Ann Surg. 2016;263:440-9.

27. George Van Buren II, Bloomston M, Hughes SJ, Winter J, Behrman SW, Zyromski NJ, et al. A randomized prospective multicenter trial of pancreaticoduodenectomy with and without routine intraperitoneal drainage. Ann Surg. 2014;259:605-12.

28. Fujii T, Sugimoto H, Yamada S, Kanda M, Suenaga M, Takami H, et al. Modified Blumgart anastomosis for pancreaticojejunostomy: technical improvement in matched historical control study. J Gastrointest Surg. 2014;18:1108-15.

29. Liu QY, Zhang WZ, Xia HT, Leng JJ, Wan T, Liang B, et al. Analysis of risk factors for postoperative pancreatic fistula following pancreaticoduodenectomy. World J Gastroenterol. 2014;20:17491-7.

30. Grobmyer SR, Kooby D, Blumgart LH, Hochwald SN. Novel pancreaticojejunostomy with a low rate of anastomotic failure-related complications. J Am Coll Surg. 2010;210:54-9.

31. Kleespies A, Rentsch M, Seeliger H, Albertsmeier M, Jauch KW, Bruns CJ. Blumgart anastomosis for pancreaticojejunostomy minimizes severe complications after pancreatic head resection. Br J Surg. 2009;96:741-50.

32. Lee YN, Kim WY. Comparison of Blumgart versus conventional duct-to-mucosa anastomosis for pancreaticojejunostomy after pancreaticoduodenectomy. Ann Hepatobiliary Pancreat Surg. 2018;22:253-60.

33. Hirono S, Kawai M, Okada Kl, Miyazawa M, Kitahata Y, Hayami S, et al. Modified Blumgart mattress suture versus conventional interrupted suture in pancreaticojejunostomy during pancreaticoduodenectomy: randomized controlled trial. Ann Surg. 2019;269:243-51.

34. Kawakatsu S, Inoue Y, Mise Y, Ishizawa T, Ito H, Takahashi Y, et al. Comparison of pancreatojejunostomy techniques in patients with a soft pancreas: Kakita anastomosis and Blumgart anastomosis. BMC Surg. 2018;18:88.

35. Wang X, Bai Y, Cui M, Zhang Q, Zhang W, Fang F, et al. Modified Blumgart anastomosis without pancreatic duct-to-jejunum mucosa anastomosis for pancreatoduodenectomy: a feasible and safe novel technique. Cancer Biol Med. 2018;15:79-87.

36. Kojima T, Niguma T, Watanabe N, Sakata T, Mimura T. Modified Blumgart anastomosis with the "complete packing method" reduces the incidence of pancreatic fistula and complications after resection of the head of the pancreas. Am J Surg. 2018;216:941-8.

37. Kawai M, Tani M, Terasawa H, Ina S, Hirono S, Nishioka R, et al. Early removal of prophylactic drains reduces the risk of intra-abdominal infections in patients with pancreatic head resection: prospective study for 104 consecutive patients. Ann Surg. 2006;244:1-7.

38. Witzigmann H, Diener MK, Kienkötter S, Rossion I, Bruckner T, Werner B, et al. No need for routine drainage after pancreatic head resection: the dual-center, randomized, controlled PANDRA trial (ISRCTN04937707). Ann Surg. 2016;264:528-37.

39. Nagakawa $Y$, Matsudo T, Hijikata $Y$, Kikuchi S, Bunso K, Suzuki Y, et al. Bacterial contamination in ascitic fluid is associated with the development of clinically relevant pancreatic fistula after pancreatoduodenectomy. Pancreas. 2013:42:701-6.

40. Kurumboor P, Palaniswami KN, Pramil K, George D, Ponnambathayil S, Varma $D$, et al. Octreotide does not prevent pancreatic fistula following pancreatoduodenectomy in patients with soft pancreas and non-dilated duct: a prospective randomized controlled trial. J Gastrointest Surg. 2015;19:2038-44.

41. Graham JA, Johnson LB, Haddad N, Al-Kawas F, Carroll J, Jha R, et al. A prospective study of prophylactic long-acting octreotide in high-risk patients undergoing pancreaticoduodenectomy. Am J Surg. 2011;201:481-5.

42. El Nakeeb A, El Gawalby A, A Ali M, Shehta A, Hamed H, El Refea M, et al. Efficacy of octreotide in the prevention of complications after pancreaticoduodenectomy in patients with soft pancreas and non-dilated pancreatic duct: a prospective randomized trial. Hepatobiliary Pancreat Dis Int. 2018;17:59-63.

\section{Publisher's Note}

Springer Nature remains neutral with regard to jurisdictional claims in published maps and institutional affiliations. 